\title{
Sub-23 nm Solid Particle Number Emission Characteristics for a Heavy-duty Engine Fuelled with Compression Natural Gas
}

\author{
Xiaowei Wang ${ }^{1}$, Lin Zhang ${ }^{1}$, Mingda Wang ${ }^{2,}{ }^{*}$, Xiaojun Jing ${ }^{1}$ and Xuejing Gu ${ }^{2}$ \\ ${ }^{1}$ CATARC Automotive Test Center (Tianjin) Co., Ltd., Tianjin 300300, China \\ ${ }^{2}$ Chinese Research Academy of Environmental Sciences;State Environmental Protection Key Laboratory of Vehicle Emission Control \\ and Simulation, Beijing 100012, China
}

\begin{abstract}
Cold and hot WHTC (World harmonized Transient-State Cycle) were separately run on the engine test bed for a heavy-duty natural gas engine fuelled with high calorific value natural gas and low calorific value natural gas. The particle emissions including PN10 (number of particles above 10nm) and PN23 (number of particles above 23nm) were measured. The results show that the transient emission of PN10 and PN23 have basically the same trends. The weighted specific emission of PN10 is 21.6 times of PN23. Cold start PN emissions account for a relatively large proportion. Fuel property has a great influence on the PN emissions of natural gas engines. The increase of carbon-containing fuels such as methane and ethane in the fuel gas will lead to a rapid increase in PN emissions especially in the cold start process. It is extremely important to strengthen the control of sub-23nm particulate emissions for heavy-duty natural gas engines.
\end{abstract}

Key words: Heavy duty natural gas engine, sub-23 nm particle, particle number, emission

\section{Introduction}

According to the "China Mobile Source Environmental Management Annual Report (2021)" released by the Ministry of Ecology and Environment [1], China's motor vehicle particulate matter emissions will reach 68,000 tons in 2020, of which diesel vehicle particulate matter emissions account for more than $90 \%$. The emission of particulate matter is harmful to the environment and human health. The environmental hazard of particulate matter mainly stems from its optical properties. The particles absorb and scatter light to reduce visibility and cause haze weather [2]. Compared with atmospheric particulate matter with larger particle size, the particulate matter emitted by motor vehicles has a small particle size with a long residence time in the atmosphere and a long transportation distance. The specific surface area of particles is larger, and it is possible to adsorb more toxic and harmful substances. Fine particles have stronger penetrating power and can penetrate into the human respiratory system and even the brain tissue [3].

The regulation of "Limits and Measurement Methods for Pollutant Emissions from Heavy Duty Diesel Vehicles (China's Sixth Phase)" [4] not only sets limitation on particulate matter quality, but also requires to count the particle number with a particle size between $23 \mathrm{~nm}-2.5 \mu \mathrm{m}$ (PN emission). The limitation of PN emission is $8 \times$ $10^{11} \# / \mathrm{kWh}$ at the World Unified Steady State Cycle
(WHSC) and $6 \times 10^{11} \# / \mathrm{kWh}$ at the World Unified Transient Cycle (WHTC), respectively.

However, laboratory tests reveal that particles in sub$23 \mathrm{~nm}$ region should not be neglected [5-9]. Studies have shown that $30 \%-50 \%$ of GDI (gasoline direct injection) engine particulate matter, and $50 \%-100 \%$ of PFI (port fuel injection) engine particulate matter, are not controlled under the current particle definition with a particle size between $23 \mathrm{~nm}-2.5 \mu \mathrm{m}$. Both European Union and China has set up working group to consider whether the emission regulations should be revised so that particles with smaller size can also be controlled and monitored . The study on sub-23 nm particles is mainly concentrated on vehicles and engines fuelled with gasoline or diesel, but less attention to engine fuelled with compression natural gas. Due to the price advantage of natural gas, heavy-duty trucks equipped with gas engines are becoming increasingly popular. The statistics shows that the cumulative sales of natural gas heavy duty trucks from January to September 2020 is 116500 in China with a year-on-year increase of nearly $29 \%$. Natural gas is considered to be a clean fuel. Reports have pointed out that the $\mathrm{HC}$ emission of natural gas vehicles can be reduced by $40 \%$, the $\mathrm{CO}$ emission can be reduced by $50 \%$, and there is no soot emission [10]. In fact, although the particle emission quality from natural gas engine is very low, its emissions contain a large number of small particulate matter, with a geometric average diameter of only $30 \mathrm{~nm}$ [11], indicating that the PN emission

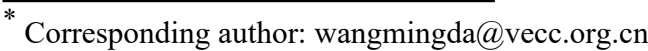


especially the fine particle need to be attached great importance. We have investigated the sub-23 nm solid particle number emission characteristics for a heavy-duty engine [12], so in this paper, we used a 10.4 L heavy-duty natural gas engine to run cold and hot WHTC on the engine test bed separately. The particle number emissions were measured by using a AVL particle counter which can simultaneously measure PN10 (number of particles with size above 10nm) and PN23 (number of particles with size above $23 \mathrm{~nm}$ ). The PN emission characteristics of heavy-duty natural gas engine with two kinds of natural gases were obtained and analyzed.

\section{Experimental Setup}

\subsection{Test equipment}

The tests were carried out on the engine test bed with a full-flow dilution sampling system (CVS). The particle number emission was measured by a particle counter developed by AVL company. The exhaust gas first goes through a volatile particle remover (VPR) to oxidize and evaporate hydrocarbons and store sulfides so as to minimize the impact on particle number counting accuracy. Then the particles in the exhaust is counting by light scattering.

The engine speed and torque were measured by AVL electric dynamometer. Other equipment used in this test includes air flow meter, intake air temperature conditioning, etc. The main test equipment is summarized in Table 1.

Table 1 Test equipment

\begin{tabular}{|c|c|}
\hline Equipment name & $\begin{array}{c}\text { Equipment Type and } \\
\text { Manufacturer }\end{array}$ \\
\hline AC Dynamometer & INDY S50-4/3001-1BV-1 \\
\hline $\begin{array}{l}\text { Test bed control } \\
\text { system }\end{array}$ & AVL PUMA Open V1.5.3 \\
\hline $\begin{array}{l}\text { Intake air } \\
\text { temperature } \\
\text { conditioning }\end{array}$ & $\begin{array}{l}\text { AVL Air Conditioning } \\
\text { System } 2400\end{array}$ \\
\hline Air flow meter & ABB SensyFlow P \\
\hline $\begin{array}{l}\text { Gaseous emission } \\
\text { measurement }\end{array}$ & AVL AMA i60 \\
\hline $\begin{array}{l}\text { Full-flow dilution } \\
\text { sampling system }\end{array}$ & AVL CVS i60 \\
\hline Particle counter & $\begin{array}{l}\text { AVL APC }{ }^{\text {plus }} \text { ADVANCED } \\
\text { with AVL CPC option for } \\
\text { sub-23nm }\end{array}$ \\
\hline $\begin{array}{c}\text { Particle quality } \\
\text { sampling equipment }\end{array}$ & AVL PSS i60 \\
\hline
\end{tabular}

\subsection{Tested engine}

The tested engine was a heavy-duty natural gas engine with a displacement of 10.4 liter with a rated power of 235 $\mathrm{kW}$ and a maximum torque of $1450 \mathrm{Nm}$. The specific parameters of the engine can be seen in Table 2 .
Table 2 Main parameters of tested engine

\begin{tabular}{cc}
\hline Parameter & Value \\
\hline Engine capacity & $10.4 \mathrm{~L}$ \\
Bore $\times$ Stroke & $128 \mathrm{~mm} \times 135 \mathrm{~mm}$ \\
Compression ratio & 12 \\
Rated power/speed & $235 \mathrm{~kW} / 1900$ \\
& $\mathrm{rpm}$ \\
Maximum torque/speed & $1450 \mathrm{Nm} / 1200$ \\
Idle speed & $\mathrm{rpm}$ \\
Emission Control Technology & $600 \mathrm{rpm}$ \\
Route & EGR+TWC \\
Emission Standards & China VI \\
\hline
\end{tabular}

\subsection{Fuels}

In this paper, two types of compression natural gas were used in accordance with the requirements of the regulations. The first is a low calorific value natural gas (NG1) which is a mixture of $85.45 \%$ methane and $14.54 \%$ nitrogen by volume fraction. The high calorific value natural gas (NG2) is a mixture of $94.11 \%$ methane, $3.5 \%$ ethane, $1.2 \% \mathrm{CO} 2$ and $1 \%$ nitrogen.

\subsection{Test plan}

In this study, WHTC was chosen as the test cycle. Except the hot WHTC (WHTC-H), the WHTC including engine cold start (WHTC-C) was also run to investigate the particle number emission characteristics under cold condition. The impact of fuel type on particle number emission was also considered in the test plan.

\section{Results and Discussions}

\subsection{PN10 and PN23 results under WHTC}

Table 3 shows the emissions of PN10 and PN23 and the weighted emissions under the hot and cold WHTC cycle. Among them, PN10 and PN23 are the measured values from the second particle counter. The weighted average $\mathrm{PN}$ emission result is calculated by the following formula.

$$
P N_{\mathrm{i}, \text { weighted }}=\frac{\left(0.14 \times P N_{i, \text { cold }}+0.86 \times P N_{i, \text { hot }}\right)}{\left(0.14 \times W_{\text {act }, \text { cold }}+0.86 \times W_{\text {act }, \text { hot }}\right)}
$$

Among then, the subscript i represents PN10 or PN23, the subscript cold and hot represents the cold WHTC and hot WHTC, W represents the cycle work.

Table 3 PN specific emission results

\begin{tabular}{cccc}
\hline & $\begin{array}{c}\text { WHTC_C( } \\
\# / \mathrm{kW} . \overline{\mathrm{h}})\end{array}$ & $\begin{array}{c}\text { WHTC_H( } \\
\# / \mathrm{kW} . \overline{\mathrm{h}})\end{array}$ & $\begin{array}{c}\text { Weighted } \\
\text { WHTC }(\# / \mathrm{kW} . \mathrm{h}\end{array}$ \\
& & & ) \\
PN23_ & $4.04 \times 10^{9}$ & $1.07 \times 10^{9}$ & $1.48 \times 10^{9}$ \\
NG1 & & & \\
PN10_ & $8.71 \times 10^{10}$ & $2.31 \times 10^{10}$ & $3.2 \times 10^{10}$ \\
NG1 & & & \\
PN23_- & $6.97 \times 10^{10}$ & $9.54 \times 10^{8}$ & $1.06 \times 10^{10}$ \\
NG2 & & \\
\hline
\end{tabular}




\begin{tabular}{cccc}
\hline $\begin{array}{c}\text { PN10 } \\
\text { NG2 }\end{array}$ & $1.50 \times 10^{12}$ & $2.06 \times 10^{10}$ & $2.27 \times 10^{11}$ \\
\hline
\end{tabular}

For these two fuels used, the weighted WHTC brake specific emission results of both PN10 and PN23 are lower than the regulation requirement of $6 \times 10^{11} \mathrm{\#} / \mathrm{kWh}$. The weighted emission of PN23 of NG1 is $1.48 \times 10^{9}$ $\# / \mathrm{kWh}$, and the weighted emission of PN10 is $3.2 \times 10^{10}$ \#/kWh. The weighted WHTC brake specific emission of PN10 is 21.6 times that of PN23. Under the cold WHTC, the brake specific emission of PN23 of NG1 is $4.04 \times 10^{9}$ $\# / \mathrm{kWh}$, and the brake specific emission of PN10 is $8.71 \times$ $10^{10} \# / \mathrm{kWh}$. For WHTC-H, the brake specific emission of PN23 of NG1 is $1.07 \times 10^{9} \# / \mathrm{kWh}$, and the brake specific emission of PN10 is $2.31 \times 10^{10} \# / \mathrm{kWh}$. Under the hot and cold WHTC cycle, the brake specific emission of PN10 is 21.6 times that of PN23. For PN23, the brake specific emission of WHTC-C is 3.78 times that of WHTC-H. For PN10, the brake specific emission of WHTC-C is 3.77 times that of WHTC-H. The weighted brake specific emission of PN23 of NG2 is $1.06 \times 10^{10} \# / \mathrm{kWh}$, and the weighted brake specific emission of PN10 is $2.27 \times 10^{11}$ \#/kWh. The weighted brake specific emission of PN10 is 21.5 times that of PN23. For WHTC-C, the brake specific emission of PN23 of NG2 is $6.97 \times 10^{10} \# / \mathrm{kWh}$, and the brake specific emission of PN10 is $1.5 \times 10^{12} \# / \mathrm{kWh}$. For WHTC-H, the brake specific emission of PN23 of NG2 is $9.53 \times 10^{8} \# / \mathrm{kWh}$, and the brake specific emission of PN10 is $2.06 \times 10^{10} \# / \mathrm{kWh}$. For both WHTC-C and WHTC-H, the brake specific emission of PN10 is 21.5 times that of PN23. For PN23, the brake specific emission of WHTC$\mathrm{C}$ is 72.99 times that of WHTC-H. For PN10, the brake specific emission of WHTC-C is 72.64 times that of WHTC-C .

It can be seen that PN10 are much higher than those of PN23 for heavy-duty natural gas engines. The main reason is that the particle size of natural gas engines is smaller. Thiruvengadam et al found that heavy-duty natural gas engine with equivalent ratio combustion equipped a three-way catalytic converter has an obvious nuclear mode peak at $10 \mathrm{~nm}$ in the particle size distribution [13]. Alanen et al found that the exhaust particles of natural gas engines have a peak size of less than $10 \mathrm{~nm}$ in diameter under steady-state conditions [14]. Hou Xianjun et al also found that the particulate matter of natural gas fuel mainly exists in the form of nuclear state [15]. All these shows that it is more urgent to control the emission of smaller particles for natural gas engines.

\subsection{PN emission characteristics under WHTC}

As shown in Figure 1, PN10 and PN23 exhibit a very consistent trend. The highest emission peak appears at the cold start phase. This is mainly due to the low exhaust temperature and the low catalytic efficiency of the threeway catalytic converter. There are two larger peaks at $700 \mathrm{~s}$ and $1200 \mathrm{~s}$. Among them, the engine is running from deceleration to idling at 700 s, which causes decreases in exhaust temperature and catalytic efficiency. At 1200s, the engine was running from acceleration to deceleration, and the air-fuel ratio control was unstable during the process, which results in incomplete combustion and increased PN emission. In the last stable high-speed stage of the cycle, the emissions of PN10 and PN23 are lower. The main reason is that the exhaust temperature is high at this time, and the particle is more likely to be oxidized.

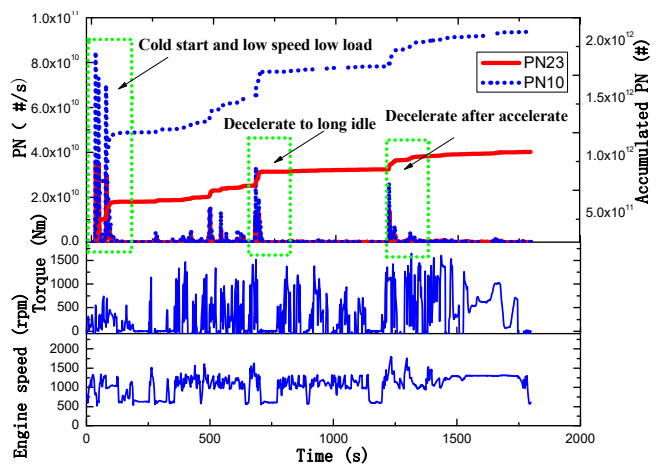

Figure 1 PN transient and accumulated emission under cold WHTC for NG1

The transient emissions and cumulative emissions of PN10 and PN23 of hot WHTC with NG1 fuel is presented in Figure 2. The trend of PN10 and PN23 is still very consistent. In the low-speed and low-load stage, the generation of particulate matter is less. Additionally, because the engine is running in a hot state, the efficiency of the three-way catalytic converter is higher. Therefore, compared with the cold state WHTC, there is no obvious peak at this stage. The largest PN emission peak appears in the acceleration to deceleration phase of about 1200 s.

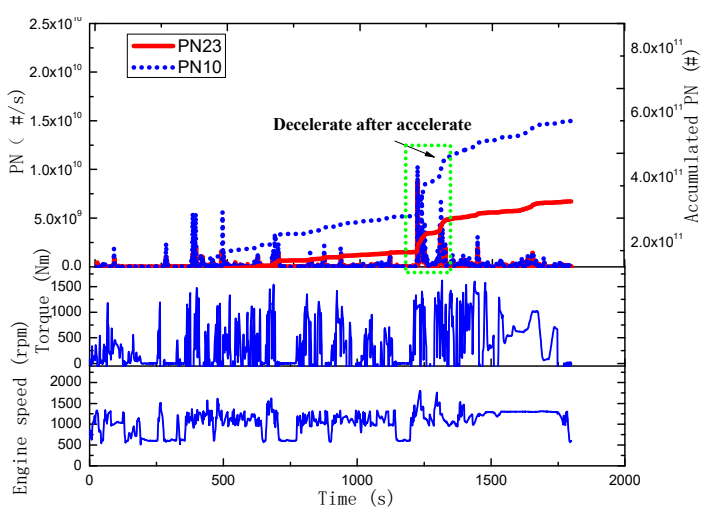

Figure $2 \mathrm{PN}$ transient and accumulated emission under hot WHTC for NG1

PN10 and PN23 emission characteristics under WHTC-C and WHTC-H with NG2 fuel are seen in Figures 3 and 4. Similar to NG1 fuel, the trends of PN10 and PN23 are very analogous. In Figure 3, the largest peak occurs during the cold start phase, and the larger peak occurs during the deceleration to long idle and acceleration to deceleration phases. However, compared with NG1 fuel, the PN emissions of NG2 fuel during the cold start phase are very serious, especially for PN10. The cumulative emissions results show that more than $95 \%$ of $\mathrm{PN}$ emissions are produced at this stage. 


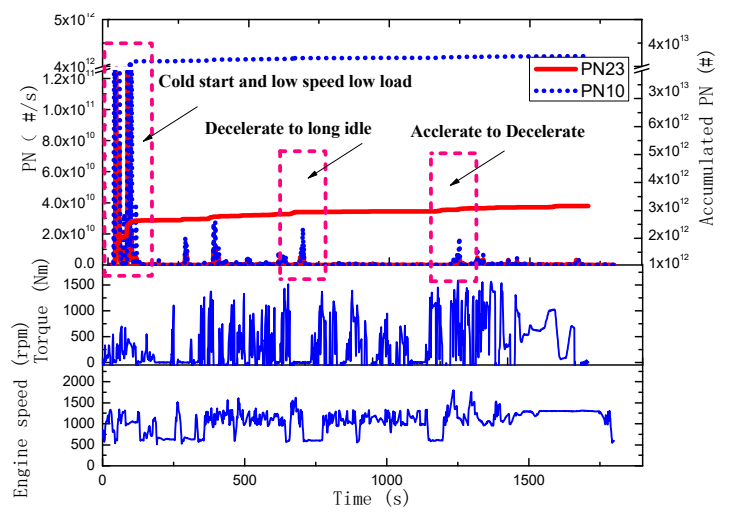

Figure 3 PN transient and accumulated emission under cold WHTC for NG2

There are fewer particles in the low-speed and low-load phases in Figure 4, and the larger particle peaks appear in the deceleration to long idle and acceleration to deceleration stages.

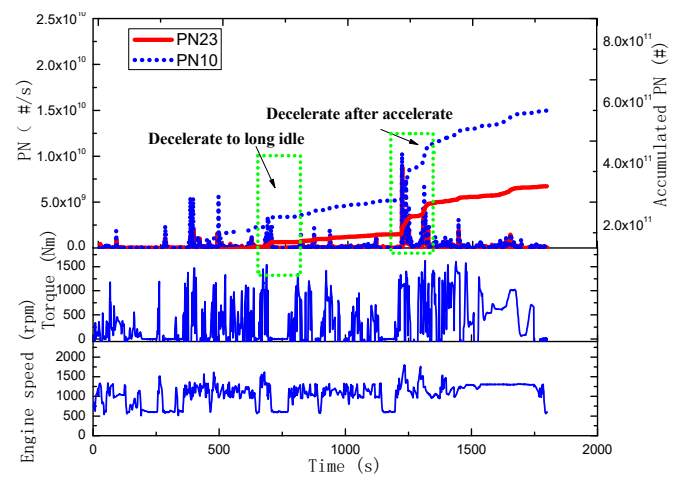

Figure $4 \mathrm{PN}$ transient and accumulated emission under hot WHTC for NG2

From the above analysis, it can be seen that PN emissions are very serious when the exhaust temperature has not reached the optimal working temperature of the three-way catalytic converter for this natural gas. When the exhaust temperature rises, operating conditions become the main influencing factor of PN emissions. In the process of acceleration and deceleration, poor control of the air-fuel ratio will result in a rich mixture in some areas of the combustion chamber, thereby increasing the emission of particulate matter. In addition, fuel has a great influence on the PN emissions, and we will conduct a detailed analysis in the next section.

\subsection{Effects of fuel on PN emissions}

Figure 5 shows the PN brake specific emission of the two different fuels in the hot and cold WHTC. In the cold WHTC, the brake specific emissions of PN10 and PN23 of the high calorific value NG2 fuel are 17.25 times and 17.2 times that of the low calorific value NG1 fuel, respectively. In the hot WHTC, the brake specific emissions of PN10 and PN23 of NG2 fuel are 0.89 times that of NG1 fuel. The fuel property has little effect on the PN emission in hot WHTC but extremely impact in cold WHTC. Combined with Figure 3, it can also be seen that the impact of NG2 fuel on PN emissions is mainly due to the cold start stage. Amirante et al. used a mixture of methane and propane in different proportions to explore the effect of fuel on emissions, and found that the addition of propane would lead to an increase in the number of particles in the size range of 5 to $30 \mathrm{~nm}$ [16]. McTaggartCowan et al. found that the addition of ethane and propane will lead to an increase in soot particulate matter emissions [17]. In this paper, the main components of NG1 fuel are methane and nitrogen, while NG2 fuel contains a certain amount of ethane in addition to the higher content of methane. The increase in carboncontaining fuels has led to an increase in PN emissions.

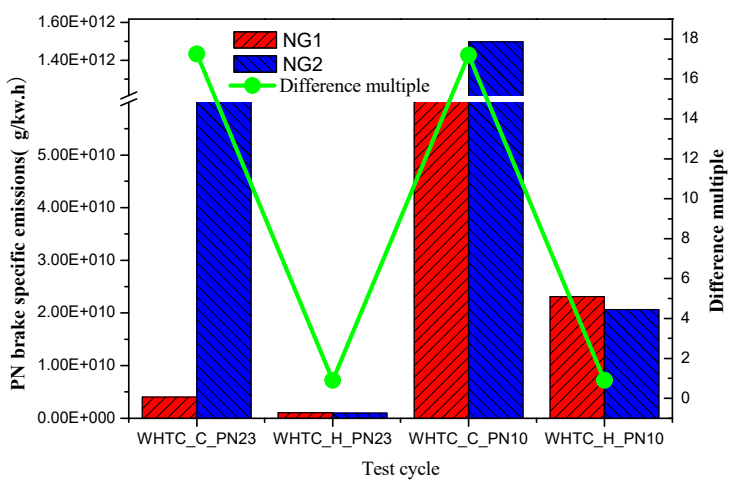

Figure 5 Brake specific emissions of PN10 and PN23 with NG1 and NG2.

Since the impact of NG2 fuel on PN emissions is mainly derived from the cold start phase of the cold WHTC cycle, the other pollutants and exhaust temperature of the two fuels during the first 150 seconds in the cold WHTC are compared, as shown in Figure 6 . It can be seen from Figure 6 that there is basically no difference in the exhaust temperature of the two fuels. The temperature rises to close to $300^{\circ} \mathrm{C}$ in less than 100 s. The total hydrocarbon (THC) and methane (CH4) emissions of NG2 fuel are slightly higher than that of NG1 fuel, but the difference is not significant. However, the carbon monoxide (CO) emission of NG2 fuel is much higher than that of NG1 fuel, and the nitrogen oxide (NOx) emission of NG1 fuel is higher than that of NG2 fuel. Therefore, it can be concluded that for the NG2 fuel, the incomplete combustion in the cold start stage is more serious than that of NG1 fuel, so the $\mathrm{CO}$ emission is much higher. This also explains why the PN emission of NG2 fuel during the cold start stage is much higher than NG1 fuel. 


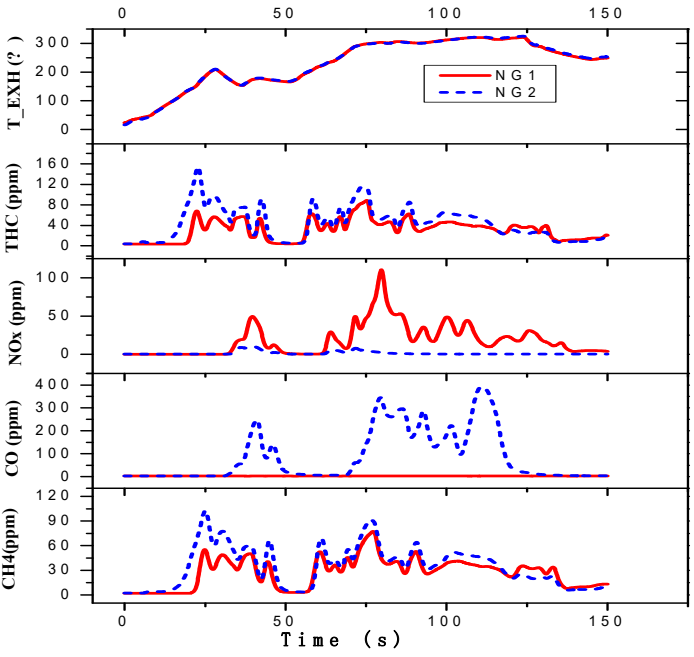

Figure 6 Emissions and exhaust temperature of engine with NG1 and NG2.

\section{Conclusion}

The heavy-duty natural gas engine was run in cold and hot WHTC, and the results showed that:

1) For heavy-duty natural gas engines, the emissions of PN10 are much higher than those of PN23. The weighted PN10 brake specific emission are 21.6 times that of the PN23. It is necessary to strengthen the control of the sub$23 \mathrm{~nm}$ PN emissions of natural gas engines.

2) The transient emission trend of PN10 and PN23 for a natural gas engines are basically the same. PN emissions at cold start stage are very serious. When the exhaust temperature rises, $\mathrm{PN}$ emissions will increase during the acceleration and deceleration process.

3) Fuel has a great influence on PN emission for natural gas engines. The increase of carbon-containing fuels such as methane and ethane in the fuel will lead to a rapid increase in PN emissions during the cold start process.

\section{References}

1. China mobile source environmental management annual report in 2021 - the situation of vehicle emission[J]. Ministry of Ecology and Environment of the People's Republic of China, 2021.

2. Nel A, Xia T, Madler L, et al. Toxic potential of materials at the nanolevel [J]. Science, 2006, 311(5761):622-627.

3. Oberdorster, G., Sharp, Z., Atudorei, V., et al. Translocation of Inhaled Ultrafine Particles to the Brain[J]. Inhal Toxicol., 2004, 16(6-7):437-45.

4. GB17691-2018 Limits and measurement methods for emissions from diesel fueled heavy-duty vehicle (Chinese VI ) [S]. Ministry of Ecology and Environment of the People's Republic of China, 2018.

5. Giechaskiel B., Vanhanen J, Väkevä M., eta al. Investigation of vehicle exhaust sub-23 nm particle
emissions[J]. Aerosol Science and Technology, 2017 51(5):626-641.

6. Hou Yuxu, Ge Yunshan, Wang Xin et al, Emission characteristics of Sub-23 nm Particle from a Turbocharged Direct-Injection Gasoline Engine[J]. Chinese Internal Combustion Engine Engineering, 2021, 42(4):24-29.

7. Stéphane Z, Mickaël L, Loïc R, et al. Measurement of Sub-23 nm particles emitted by gasoline direct injection engine with new advanced instrumentation [C], SAE 2019-01-2195.

8. Leach, F., Lewis, A., Akehurst, S., Turner, J. et al., Sub-23 nm Particulate Emissions from a Highly Boosted GDI Engine[C], SAE 2019-24-0153.

9. Khan, M.Y., Peng, W., Scott, N., Lin, Y. et al., Heavy-Duty Engines Exhaust Sub-23 nm Solid Particle Number Measurements[C], SAE 2021-015024.

10. Elia D, Riccardo A, Giuseppe C, et al. Evolution of Soot Particle Number, Mass and Size Distribution along the Exhaust Line of a Heavy-Duty Engine Fueled with Compressed Natural Gas[J]. Energies 2020, 13 (15):3993.

11. Hajbabaei M, Karavalakis G, Johnson K C, et al. Impact of natural gas fuel composition on criteria, toxic, and particle emissions from transit buses equipped with lean burn and stoichiometric engines. Energy, 2013, 62: 425-434.

12. Xiaowei Wang, Xiaojun Jing, Xuejing Gu, et al. Future Regulationbased Particle Number Emission Characteristics for a Heavyduty Diesel Engine, IOP Conference Series: Earth and Environmental Science, 2021

13. Thiruvengadam A, Besch MC, Yoon S, et al, Characterization of particulate matter emissions from a current technology natural gas engine[J]. Environ Sci Technol. 2014 Jul 15;48(14):8235-42.

14. Alanen J, Saukko E, Lehtoranta K, et al, The formation and physical properties of the particle emissions from a natural gas engine[J]. Fuel, 2015 162:155-161.

15. Hou Xianjun, Xiong Na, Wang Youheng, et al., Particulate Matter Emission Characteristics of Gasoline/Compressed Natural Gas Dual-Fuel Engine[J]. Chinese Internal Combustion Engine Engineering, 2021, 42(3):74-80.

16. Amirante R, Distaso E, Di Iorio S,et al. Effects of natural gas composition on performance and regulated, greenhouse gas and particulate emissions in spark-ignition engines[J]. Energy Convers. Manag. 2017, 143:338-347.

17. McTaggart-Cowan GP, Rogak SN, Munshi S R, et al The influence of fuel composition on a heavy-duty, natural-gas direct-injection engine[J]. Fuel 2010, 89: $752-759$. 